\title{
Periodontal Health of Children with Type 1 Diabetes Mellitus in Kuwait: A Case-Control Study
}

\author{
Areej K. Al-Khabbaz ${ }^{\text {a }}$ Khalaf F. Al-Shammari ${ }^{\text {a }}$ Abdulaziz Hasan ${ }^{\text {b }}$ \\ Majedah Abdul-Rasoul ${ }^{\mathrm{C}}$ \\ Departments of a Surgical Sciences and ${ }^{b}$ Developmental and Preventive Sciences, Faculty of Dentistry, and \\ 'Department of Pediatrics, Faculty of Medicine, Kuwait University, Jabriya, Kuwait
}

\section{Key Words}

Type 1 diabetes mellitus $\cdot$ Periodontal diseases $\cdot$ Children

\begin{abstract}
Objective: The aim of this study was to evaluate periodontal health in children diagnosed with type 1 diabetes mellitus.

Subjects and Methods: Periodontal health was clinically examined and compared in 95 children diagnosed with type 1 diabetes and 61 healthy control subjects (4-14 years old). Plaque index, gingival index, clinical attachment loss and bleeding on probing were assessed on the 6 Ramfjord index teeth. Diabetes history was recorded based on information provided by the physician from the medical record of each diabetic child. Diabetes history included date of diagnosis, diabetes duration, age at diagnosis, latest reading for glycosylated hemoglobin and any existing diabetes complications. Data were analyzed using the Statistical Package for Social Science software, version 18. 'Periodontitis' was defined as at least one site with clinical attachment loss $>2 \mathrm{~mm}$ on at least 2 teeth. Results: Sixty-two of the diabetic children (65\%) had poor compliance with dental care, and 42 of them (44\%) had never visited the dentist before. The children with
\end{abstract}

\section{KARGER}

E-Mail karger@karger.ch www.karger.com/mpp

\section{() 2012 S. Karger AG, Basel 1011-7571/13/0222-0144\$38.00/0}

Karger

Open access

This is an Open Access article licensed under the terms of the Creative Commons Attribution- NonCommercial-NoDerivs 3.0 License (www.karger.com/OA-license), applicable to the online version of the article only. Distribution for non-commercial purposes only. type 1 diabetes mellitus had a significantly higher plaque index and gingival index and more bleeding on probing than control subjects $(p<0.001)$. In the diabetic group, periodontitis was significantly associated with longer duration of diabetes (odds ratio 2.230, confidence interval 1.308$3.801 ; p=0.003$ ) and older age at diagnosis of diabetes (odds ratio 1.838 , confidence interval $1.091-3.096 ; p=0.022$ ). Conclusions: Periodontal disease in young patients with type 1 diabetes was more evident than in those without diabetes. These data showed that diabetes duration may play a significant role in the progression of periodontal disease in diabetic children.

Copyright $\odot 2012$ S. Karger AG, Basel

\section{Introduction}

The most prevalent periodontal disease among children is gingivitis [1], and it usually becomes more severe in adolescence [2]. If gingivitis is not treated and properly managed, it may progress to periodontitis [3]. Patients diagnosed with diabetes mellitus are considered a high-risk group with greater susceptibility to severe

Assist. Prof. Areej K. Al-Khabbaz, DDS, MS

Department of Surgical Sciences, Faculty of Dentistry, Kuwait University PO Box 24923

Safat 13110 (Kuwait)

E-Mail areejalkhabbaz@hsc.edu.kw 
forms of periodontal destruction that may lead to tooth loss [4]. Several studies have demonstrated that the prevalence, severity and progression of periodontal disease are significantly increased in patients with diabetes $[5,6]$. A few reports on the relationship between diabetes and periodontal disease have included children and adolescents [7-11]. Most of the studies evaluating the relationship between diabetes and periodontal disease in children did not specify the type of diabetes and used selfreported medical information.

The prevalence of type 1 diabetes is increasing noticeably among children in Kuwait [12]. The reported incidence rate of type 1 diabetes was 20.1 per 100,000 children aged 0-14 years [13]. Risk factors for diabetes in young individuals included a family history of diabetes and diet [14]. Although the prevalence and incidence of diabetes are increasing dramatically among children in Kuwait, at present there are no available studies or published material evaluating the periodontal condition of diabetic children in Kuwait. Therefore, the aims of this study were to assess periodontal health in children with type 1 diabetes mellitus and to explore the diabetes-related parameters that are associated with periodontal destruction.

\section{Subjects and Methods}

\section{Subjects}

This cross-sectional study was approved by the Ethics Review Committee of the Faculty of Dentistry, Kuwait University, and conducted during 2010-2011. Ninety-five children with diabetes were mainly recruited from the Diabetic Unit at Mubarak Hospital, and 61 controls were recruited from the Dental Clinic of Kuwait University. Inclusion criteria for the diabetic group were: an established diagnosis of type 1 diabetes for at least 1 year, a minimum age of 4 years and the ability to undergo a dental examination. General exclusion criteria for all participants were: need for antibiotic prophylaxis, a history of recent systemic antibiotic therapy and orthodontic appliances. All participants and their guardians were informed about the aim of the study and its voluntary nature, and informed consent was obtained from parents prior to enrolment. Nondiabetic children were matched to the diabetic children based on frequency matching. No bias in selection occurred since patients were chosen in the order of random admission. The dental examination for the diabetic children was performed on the same day directly following their annual medical assessment. Because of unavoidable logistical obstacles, the examiners (A.K.A., A.H.) were not masked to the diabetic status of the participants. All the diabetic patients had their glycosylated hemoglobin (HbA1c) test 1-7 day(s) prior to their annual medical visit. The referring physician provided the diabetic history for each patient based on the information in the medical record of each diabetic child. Diabetic history included date of diagnosis, duration of diabetes, age at diagnosis, latest reading for $\mathrm{HbAlc}$ and any existing diabetic complications. Control subjects were considered medically healthy based on their self-reported medical history, which was obtained from the parents (if the patient was not on any medication and had never been told by a physician that he or she had diabetes or any other medical conditions). For all the study subjects, data collection comprised sociodemographic information, dental history and oral hygiene practice.

\section{Periodontal Assessment}

The periodontal examination was based on the 6 Ramfjord index teeth [15]. For patients with deciduous and mixed dentition, the periodontal examination was carried out on the corresponding teeth. The plaque index [16] and gingival index [17] were assessed on 4 sites per tooth (mesiobuccal, distobuccal, mesiolingual and distolingual). The plaque index was scored on a scale of $0-3$ as follows: 0 = no plaque; 1 = subgingival plaque only detectable with probe; 2 = visible plaque; $3=$ abundant plaque covering the tooth. The gingival index was used to detect signs of inflammation and was also scored on a scale of $0-3$ as follows: $0=$ normal gingiva; 1 = mild inflammation/slight color change or edema; $2=$ moderate inflammation/redness and edema; 3 = severe inflammation with marked redness and edema and/or tendency for spontaneous bleeding. For fully erupted permanent teeth, clinical attachment loss and bleeding on probing were recorded for 6 sites per tooth (mesiobuccal, midbuccal, distobuccal, mesiolingual, midlingual and distolingual). Clinical attachment loss represents the distance from the cementoenamel junction to the bottom of the periodontal pocket. Bleeding on probing was recorded as either present or absent within $30 \mathrm{~s}$ after probing. All assessments were performed by 1 of 2 trained examiners (A.A. and A.H.) using a standardized manual periodontal probe. The examiners demonstrated clinical attachment loss measurements across a range of subjects (who were recruited for the purpose of the calibration and training exercise) at $\pm 1 \mathrm{~mm}$ over $90 \%$ of the time. At the end of the clinical examination, each patient was informed of the clinical findings, given oral hygiene instructions and referred for periodontal treatment as needed.

\section{Statistical Analysis}

Data were entered and analyzed using the Statistical Package for Social Science software (SPSS, Chicago, Ill., USA), version 18. Descriptive statistics were generated for all the study variables. $\chi^{2}$ test was performed to detect significant associations between categorical variables, and the Student $t$ test was used for continuous variables. Statistical analysis of clinical findings was performed to detect differences between diabetic subjects and controls and to detect differences between diabetic subjects with different diabetes duration and $\mathrm{HbAlc} \%$. Binary logistic regression analysis was performed in order to examine which factors were significant in multivariate analysis after adjusting for confounding between effects. The first regression model used the dependent variable 'having type 1 diabetes', and the independent variables entered in the model were plaque index, gingival index, bleeding on probing and clinical attachment loss. The second regression model used the dependent variable 'periodontitis' in the diabetic children. 'Periodontitis' was defined as at least 1 site with clinical attachment loss $>2 \mathrm{~mm}$ on at least 2 teeth. Independent variables entered in the model were diabetes duration, age at diagnosis and $\mathrm{HbA} 1 \mathrm{c} \%$. Statistical significance was set at $\mathrm{p}<0.05$. 
Table 1. Sociodemographic characteristics and diabetes history

\begin{tabular}{llll}
\hline Variable & $\begin{array}{l}\text { Case subjects } \\
(\mathrm{n}=95)\end{array}$ & $\begin{array}{l}\text { Control subjects } \\
(\mathrm{n}=61)\end{array}$ & $\begin{array}{l}\mathrm{p} \\
\text { value }\end{array}$ \\
\hline $\begin{array}{l}\text { Age, years } \\
\text { Gender }\end{array} \quad 9.1 \pm 3.9$ & $8.9 \pm 2.2$ & 0.903 \\
$\quad$ Male & $53(55.8 \%)$ & $32(52.5 \%)$ & 0.743 \\
$\quad$ Female & $42(44.2 \%)$ & $29(47.5 \%)$ & \\
$\begin{array}{l}\text { Diabetes history, years } \\
\text { Age at diagnosis, }\end{array}$ & $6.0 \pm 3.7$ & & \\
$\quad$ & & & \\
$\quad$ years & $2.9 \pm 2.9$ & & \\
\hline
\end{tabular}

\section{Results}

The mean age of the participants was $9.04 \pm 3.31$ years (range 4-14). The sociodemographic characteristics and diabetic history of the study participants are presented in table 1. No statistical difference was found between diabetic patients and controls with regard to gender distribution, with 53 male diabetics (55.8\%) and 32 male controls (52.5\%; $\mathrm{p}=0.526)$. Regarding diabetes history, age of diagnosis ranged from birth to 13 years old; 43 of the diabetic children (45.0\%) were diagnosed with diabetes at $>6$ years. Dental history and oral hygiene practice of the study population are presented in table 2 . A statistical difference was found between the two groups in terms of the last dental visit and brushing frequency $(\mathrm{p}=0.001$ and 0.014 , respectively). There was also a significant difference in age at the first dental visit $(\mathrm{p}<0.001)$, whereby 42 of the diabetic children (44.2\%) had never visited the dentist before and only 23 (24\%) had visited the dentist at age 4 or younger, whereas 25 of the controls (41\%) had started to visit the dentist at age 4 or younger.

Periodontal clinical characteristics of the study population are given in table 3 . Children with diabetes had significantly more dental plaque $(\mathrm{p}<0.001)$, a higher gingival index and more bleeding on probing than nondiabetic control children. There was no statistically significant difference between the two groups in terms of clinical attachment loss. After performing adjusted analysis for all the periodontal parameters, a higher mean gingival index was the only parameter significantly associated with children diagnosed with type 1 diabetes (odds ratio 4.060, confidence interval 1.383-11.918; $\mathrm{p}=0.011)$. The mean values of variables describing the clinical periodontal condition among diabetic children with different diabetes duration and different $\mathrm{HbAlc} \%$ are presented in ta-
Table 2. Dental history and oral hygiene practice

\begin{tabular}{lcll}
\hline Variable & $\begin{array}{l}\text { Case } \\
\text { subjects } \\
\mathrm{n}(\%)\end{array}$ & $\begin{array}{l}\text { Control } \\
\text { subjects } \\
\mathrm{n}(\%)\end{array}$ & $\begin{array}{l}\mathrm{p} \\
\text { value }\end{array}$ \\
\hline $\begin{array}{l}\text { Reported age at first dental visit } \\
\leq 4 \text { years }\end{array}$ & $23(24.2)$ & $25(41.0)$ & \\
$\quad>4$ years & $30(31.6)$ & $32(52.5)$ & \\
$\quad$ Never visited a dentist before & $42(44.2)$ & $4(6.6)$ & \\
Last dental visit & $25(26.3)$ & $29(47.5)$ & \\
$\quad<6$ months & $8(8.4)$ & $18(29.5)$ & \\
$\quad$ 6-12 months & $20(21.1)$ & $10(16.4)$ & \\
$\quad>12$ months & & & 0.014 \\
Brushing frequency & $25(26.3)$ & $24(39.3)$ & \\
$\quad \geq 2$ times/day & $34(35.8)$ & $27(44.3)$ & \\
$\quad \begin{array}{l}\text { Once a day } \\
\text { Occasional/never }\end{array}$ & $36(37.9)$ & $10(16.4)$ & \\
\hline
\end{tabular}

Table 3. Clinical findings and periodontal characteristics

\begin{tabular}{llll}
\hline Variable & $\begin{array}{l}\text { Case } \\
\text { subjects }\end{array}$ & $\begin{array}{l}\text { Control } \\
\text { subjects }\end{array}$ & $\begin{array}{l}\mathrm{p} \\
\text { value }\end{array}$ \\
\hline Plaque index & $1.8 \pm 0.7$ & $1.3 \pm 0.4$ & $<0.001$ \\
Gingival index & $1.9 \pm 1.1$ & $0.9 \pm 0.5$ & $<0.001$ \\
Bleeding on probing & $0.4 \pm 0.3$ & $0.1 \pm 0.2$ & $<0.001$ \\
Clinical attachment loss, $\mathrm{mm}$ & $2.6 \pm 0.5$ & $2.4 \pm 0.3$ & 0.260 \\
\hline
\end{tabular}

Values represent means \pm SD. Plaque index and gingival index were each scored on a scale of $0-3$.

ble 4. Diabetes duration ranged from 1 to 14 years [ 45 of the diabetic children (47.4\%) had had diabetes for $>2$ years], and 47 children diagnosed with type 1 diabetes (50.0\%) had an $\mathrm{HbAlc}$ reading $>9 \%$. Patients diagnosed with type 1 diabetes with $>2$ years' duration had significantly more mean clinical attachment loss and bleeding on probing ( $\mathrm{p}=0.021$ and 0.014 , respectively). In addition, poor glycemic control (HbAlc $>9 \%$ ) in diabetic patients had a significant effect on increasing the mean plaque index $(\mathrm{p}<0.001)$, gingival index $(\mathrm{p}=0.024)$ and clinical attachment loss $(\mathrm{p}=0.041)$. The logistic regression analysis of factors associated with having 'periodontitis' (at least 1 site with clinical attachment loss $>2 \mathrm{~mm}$ on at least 2 teeth) is presented in table 5 . Longer diabetes duration and having been diagnosed with diabetes at an older age were the most significant variables associated with having periodontitis. 
Table 4. Periodontal findings for diabetic subjects according to diabetes history

\begin{tabular}{|c|c|c|c|c|c|c|}
\hline \multirow[t]{2}{*}{ Variables } & \multicolumn{2}{|c|}{ Diabetes duration } & \multirow{2}{*}{$\begin{array}{l}\mathrm{p} \\
\text { value }\end{array}$} & \multicolumn{2}{|l|}{ HbAlc } & \multirow{2}{*}{$\begin{array}{l}\mathrm{p} \\
\text { value }\end{array}$} \\
\hline & $\begin{array}{l}\leq 2 \text { years } \\
(\mathrm{n}=50)\end{array}$ & $\begin{array}{l}>2 \text { years } \\
(\mathrm{n}=45)\end{array}$ & & $\begin{array}{l}\leq 9 \% \\
(n=48)\end{array}$ & $\begin{array}{l}>9 \% \\
(n=47)\end{array}$ & \\
\hline Plaque index & $1.7 \pm 0.8$ & $1.9 \pm 0.7$ & 0.089 & $1.5 \pm 0.5$ & $2.0 \pm 0.8$ & $<0.001$ \\
\hline Gingival index & $1.6 \pm 1.03$ & $2.06 \pm 1.1$ & 0.070 & $1.6 \pm 0.9$ & $2.2 \pm 1.2$ & 0.024 \\
\hline Clinical attachment loss, $\mathrm{mm}$ & $2.4 \pm 0.5$ & $2.7 \pm 0.5$ & 0.021 & $2.3 \pm 0.5$ & $2.7 \pm 0.5$ & 0.041 \\
\hline Bleeding on probing & $0.2 \pm 0.3$ & $0.4 \pm 0.3$ & 0.014 & $0.3 \pm 0.2$ & $0.4 \pm 0.3$ & 0.246 \\
\hline
\end{tabular}

Plaque index and gingival index were each scored on a scale of $0-3$.

Table 5. Logistic regression analysis of factors associated with having periodontitis in diabetic children

\begin{tabular}{lrrr}
\hline Factor & B & OR & $\begin{array}{l}\mathrm{p} \\
\text { value }\end{array}$ \\
\hline Diabetes duration & $0.80(0.27)$ & $2.23(1.30-3.80)$ & 0.003 \\
Age at diagnosis of DM & $0.60(0.26)$ & $1.83(1.09-3.09)$ & 0.022 \\
HbA1c & $-0.06(0.14)$ & $0.93(0.70-1.24)$ & 0.648 \\
\hline
\end{tabular}

Periodontitis was defined as at least 1 site with clinical attachment loss $>2 \mathrm{~mm}$ on at least 2 teeth. Figures in parentheses represent standard errors or $95 \%$ confidence intervals, as appropriate. $\mathrm{OR}=$ Adjusted odds ratio; $\mathrm{B}=$ coefficient $; \mathrm{DM}=$ diabetes mellitus .

\section{Discussion}

Children with diabetes endure many problems, including oral health complications $[7,18,19]$ as observed in this study. Although the mean clinical attachment loss was not significantly different between the two groups in this study, diabetic children had significantly more plaque accumulation and gingival inflammation than nondiabetic children (table 3), similar to the study of Lal et al. [19], which reported that diabetic children had an increased risk of gingival bleeding of about $35-57 \%$ greater than that for controls. It has been shown that patients with type 1 diabetes mount an exaggerated gingival inflammatory response to a bacterial challenge compared to that found in nondiabetics [20]. In addition, diabetic patients may have more Gram-negative bacteria than controls [21]. Generally, our results confirmed that diabetes is a risk factor for periodontal inflammation in children as previously reported $[3,4,7,18]$.

When studying young individuals, it is essential to evaluate periodontal changes at the gingival level and the connective tissue level. Our data showed that patients with type 1 diabetes with longer diabetes duration $(>2$ years) had significantly higher mean clinical attachment loss and more bleeding on probing compared to diabetic patients with shorter diabetes duration (table 4). After adjustment for other predictors in the regression model, the estimated odds that diabetic patients with longer diabetes duration had periodontitis were 2.230 times the odds for diabetic patients with shorter duration. These findings suggest that in young patients with type 1 diabetes, the longer disease duration could influence the initiation of gingival inflammation and its progression to periodontitis. This suggestion agrees with that made by Dakovic and Pavlovic [9] in Serbia, that there is a significant association between clinical attachment loss and diabetes duration. On the other hand, other investigators $[18,22]$ could not confirm this association using several definitions for periodontitis. Some investigators [22] found that individuals with diabetes and poor metabolic control are at higher risk for more severe periodontitis, whereas other investigators [23] could not confirm this association. In our study, patients with type 1 diabetes with better glycemic control (HbAlc $\leq 9 \%$ ), a significantly lower mean gingival index and plaque index and less clinical attachment loss compared to diabetic patients with poor glycemic control (HbAlc >9\%). However, in the regression analysis we could not confirm a significant correlation between $\mathrm{HbAlc}$ and periodontitis. There are several possible reasons for not observing a strong association between periodontal attachment loss and glycemic control in this sample. One of the reasons is the limitation of using a single HbAlc measurement. It might be possible to suggest that the poor glycemic control over the last 3 months was more closely correlated with gingival inflammation than connective tissue attachment loss in this sample. Measures of glycemic control and periodon- 
tal disease represent different time periods in an individual's life; HbAlc represents the glycemic status in the previous 3 months, while periodontal disease measures the cumulative impact of periodontal destruction over an individual's lifetime. Therefore, it might be more useful to use the HbAlc measurements over the previous 12 24 months and correlate the average with periodontal attachment loss. Lalla et al. [22] did not find an association between clinical attachment loss and HbAlc in a sample of children with type 1 and type 2 diabetes. However, when they used a definition of periodontal disease that included gingival bleeding in addition to clinical attachment loss, periodontal disease was associated with $\mathrm{HbAlc}$.

A previous study had shown an association between severe periodontal disease and both type 1 and type 2 diabetes mellitus [5]. Diabetes may influence the periodontium in several ways, including alteration of connective tissue metabolism, alteration of the host immune response and function of immune cells and the upregulation of monocytes, which might lead to uncontrolled release of inflammatory mediators [6]. Current evidence regarding the biological link between diabetes and periodontal disease supports persisting hyperglycemia leading to an exaggerated immunoinflammatory response to the periodontal pathogenic bacterial challenge [24]. Therefore, gingival bleeding at a young age may have some prognostic value for future risk of periodontal disease over a period of time in diabetic children. In our study, the estimated odds that diabetic patients diagnosed at an older age had periodontitis were 1.838 times the odds for diabetic patients diagnosed at a younger age. This finding is probably due to the overwhelming confounding effect of puberty [3]. Gingivitis is usually more prevalent and severe in adolescence [25]. In addition, puberty adversely impacts insulin action and HbAlc control [26]. In comparison with studies in diabetic children from the USA $[7,18]$ and Europe $[9,27]$, diabetic children in Kuwait had higher values for the plaque index and gin- gival index. Interestingly, in our study only $24 \%$ of the diabetic children had their first dental visit before the age of 4 years, and a large number of them (44\%) had never visited the dentist before. Apparently, the current health service in Kuwait provides free access to dental care to all Kuwaiti nationals, and parents should be encouraged to use these services. However, Kuwaiti diabetic children and their parents may have a negative attitude towards dental health and limited knowledge of the potential impact of diabetes on oral and periodontal health. Al-Shammari et al. [28] showed that one of the strongest factors for not attending regular preventive dental visits was the belief that dental visits were only necessary if there was pain. Other recent studies in Kuwait $[29,30]$ have also indicated that knowledge about the effects of diabetes on periodontal health among medical and dental practitioners is generally low. Therefore, the attitude towards the importance of dental health and its integration within the general health care system should be emphasized, especially given that chronic health problems such as diabetes are highly prevalent among adults and children in Kuwait [12].

\section{Conclusion}

The findings of this study showed that children with diabetes mellitus type 1 exhibited significantly more gingival inflammation than healthy children. Diabetes duration appeared to have played a significant role in the development of periodontitis.

\section{Acknowledgment}

This study was supported by Kuwait University (research grant No. RD 01/09).

\section{References}

1 Stamm JW: Epidemiology of gingivitis. J Clin Periodontol 1986;13:360-370.

-2 Nakagawa S, Fujii H, Machida Y, Okuda K: A longitudinal study from prepuberty to $\mathrm{pu}$ berty of gingivitis. Correlation between the occurrence of Prevotella intermedia and sex hormones. J Clin Periodontol 1994;21:658665 .
-3 Albandar JM, Tinoco EM: Global epidemiology of periodontal diseases in children and young persons. Periodontol 2000 2002;29: 153-176.

-4 Grossi SG, Zambon JJ, Ho AW, Koch G, Dunford RG, Machtei EE, Norderyd OM, Genco RJ: Assessment of risk for periodontal disease. I. Risk indicators for attachment loss. J Periodontol 1994;65:260-267.
-5 Taylor GW, Borgnakke WS: Periodontal disease: associations with diabetes, glycemic control and complications. Oral Dis 2008; 14 : 191-203.

6 6 Mealey BL, Oates TW: Diabetes mellitus and periodontal diseases. J Periodontol 2006;77: 1289-1303. 
7 Lalla E, Cheng B, Lal S, Kaplan S, Softness B, Greenberg E, Goland RS, Lamster IB: Diabetes mellitus promotes periodontal destruction in children. J Clin Periodontol 2007;34: 294-298.

-8 Arrieta-Blanco JJ, Bartolome-Villar B, Jimenez-Martinez E, Saavedra-Vallejo P, Arrieta-Blanco FJ: Dental problems in patients with diabetes mellitus (II): gingival index and periodontal disease. Med Oral 2003;8: 233-247.

-9 Dakovic D, Pavlovic MD: Periodontal disease in children and adolescents with type 1 diabetes in Serbia. J Periodontol 2008;79: 987-992.

10 Pinson M, Hoffman WH, Garnick JJ, Litaker MS: Periodontal disease and type I diabetes mellitus in children and adolescents. J Clin Periodontol 1995;22:118-123.

11 Gusberti FA, Syed SA, Bacon G, Grossman $\mathrm{N}$, Loesche WJ: Puberty gingivitis in insulindependent diabetic children. I. Cross-sectional observations. J Periodontol 1983;54: 714-720.

12 Moussa MA, Alsaeid M, Abdella N, Refai TM, Al-Sheikh N, Gomez JE: Prevalence of type 1 diabetes among 6- to 18 -year-old $\mathrm{Ku}$ waiti children. Med Princ Pract 2005;14:8791.

13 Shaltout AA, Moussa MA, Qabazard M, Abdella N, Karvonen M, Al-Khawari M, AlArouj M, Al-Nakhi A, Tuomilehto J, ElGammal A: Further evidence for the rising incidence of childhood type 1 diabetes in Kuwait. Diabet Med 2002;19:522-525.
14 Moussa MA, Alsaeid M, Refai TM, Abdella N, Al-Sheikh N, Gomez JE: Factors associated with type 1 diabetes in Kuwaiti children. Acta Diabetol 2005;42:129-137.

15 Ramfjord SP: The periodontal disease index (PDI). J Periodontol 1967;38(suppl):602-610.

16 Silness J, Loe H: Periodontal disease in pregnancy. II. Correlation between oral hygiene and periodontal condition. Acta Odontol Scand 1964;22:121-135.

17 Loe H, Silness J: Periodontal disease in pregnancy. I. Prevalence and severity. Acta Odontol Scand 1963;21:533-551.

18 Lalla E, Cheng B, Lal S, Tucker S, Greenberg E, Goland R, Lamster IB: Periodontal changes in children and adolescents with diabetes: a case-control study. Diabetes Care 2006;29: 295-299.

19 Lal S, Cheng B, Kaplan S, Softness B, Greenberg E, Goland RS, Lalla E, Lamster IB: Gingival bleeding in 6- to 13-year-old children with diabetes mellitus. Pediatr Dent 2007;29: 426-430.

20 Salvi GE, Kandylaki M, Troendle A, Persson GR, Lang NP: Experimental gingivitis in type 1 diabetics: a controlled clinical and $\mathrm{mi}-$ crobiological study. J Clin Periodontol 2005; 32:310-316.

-21 Sandholm L, Swanljung O, Rytomaa I, Kaprio EA, Maenpaa J: Morphotypes of the subgingival microflora in diabetic adolescents in Finland. J Periodontol 1989;60:526528.

22 Lalla E, Cheng B, Lal S, Kaplan S, Softness B, Greenberg E, Goland RS, Lamster IB: Diabetes-related parameters and periodontal conditions in children. J Periodontal Res 2007; 42:345-349.
23 Sandholm L, Swanljung O, Rytomaa I, Kaprio EA, Maenpaa J: Periodontal status of Finnish adolescents with insulin-dependent diabetes mellitus. J Clin Periodontol 1989;16: 617-620.

24 Nishimura F, Iwamoto Y, Soga Y: The periodontal host response with diabetes. Periodontol 2000 2007;43:245-253.

25 Jenkins WM, Papapanou PN: Epidemiology of periodontal disease in children and adolescents. Periodontol 2000 2001;26:16-32.

26 Amiel SA, Sherwin RS, Simonson DC, Lauritano AA, Tamborlane WV: Impaired insulin action in puberty. A contributing factor to poor glycemic control in adolescents with diabetes. N Engl J Med 1986;315:215-219.

-27 Aren G, Sepet E, Ozdemir D, Dinccag N, Guvener B, Firatli E: Periodontal health, salivary status, and metabolic control in children with type 1 diabetes mellitus. J Periodontol 2003;74:1789-1795.

- 28 Al-Shammari KF, Al-Ansari JM, Al-Khabbaz AK, Honkala S: Barriers to seeking preventive dental care by Kuwaiti adults. Med Princ Pract 2007;16:413-419.

29 Al-Khabbaz AK, Al-Shammari KF, Al-Saleh NA: Knowledge about the association between periodontal diseases and diabetes mellitus: contrasting dentists and physicians. J Periodontol 2011;82:360-366.

30 Al-Khabbaz AK, Al-Shammari KF: Diabetes mellitus and periodontal health: dentists' knowledge. Med Princ Pract 2011;20:538544. 